\section{Floral Initiation and Vascular Development in Lateral Buds of Kalanchoe}

\author{
Raymond Kessler1 and Stan P. Myers $\mathbf{s}^{2}$ \\ Department of Horticulture, Mississippi State University, Mississippi \\ State, MS 39762
}

Additional index words .photoperiod, Kalanchoe blossfeldiana

\begin{abstract}
Early development of lateral buds is demonstrated as one of the evocation events in Kalanchoes (Kalanchoe blossfeldiana Poelln.). Lateral buds of 'Cactus Candy', 'Gelbe Melody', and 'Jupiter' that were $\approx 5 \mathrm{~mm}$ long or less showed no signs of a change to the reproductive state after 21 short days. However, larger lateral buds for 'Jupiter' did show floral initiation while those of 'Cactus Candy' and 'Gelbe Melody' did not. Studies of the vascular arrangement indicate the presence of four dorsal and four ventral bundles connecting leaves to the stem. Vascular connections to lateral buds arise from vascular cambium but do not appear to connect to any of the bundles that supply leaves.
\end{abstract}

Morphological events occurring in the shoot tip of $K$. blossfeldian a during floral initiation and development have previously been described for several cultivars (Fredericq, 1960; Roodenburg, 1939; Stein and Stein, 1960). Coincident with this process, active development of previously formed lateral buds just below the apex is resumed. Depending on the number of short days received by plants, many of these lateral buds will initiate flower buds and contribute to the overall floral canopy (Roodenburg, 1939).

The uppermost set of maturing leaves is the most sensitive in the perception of photoperiod by kalanchoes (Runger, 1968). Induction of the terminal apex appears to precede that of lateral branches even when a single induced leaf subtends an axillary shoot. Work on translocation of the flowering stimulus has concentrated on movement of the hypothetical succulence-inducing factor 'Metaplasin' (Harder and Gummer, 1944) or a photomorphogenic stimulus (Stein and Stein, 1960) that appears to move to the apex in the same orthostichery above a single induced leaf, but with some lateral spread. The same pathway may be involved in the movement of the flowering stimulus. Harder and Witsch (1940) proposed that the floral stimulus is transmitted along vascular strands to the apex and a functional phloem is necessary. However, when a leaf under long days was interposed between an induced leaf and the apical meristem, flowering was delayed and the inhibitory effect was restricted to the

Received for publication 3 June 1991. Accepted for publication 20 Sept. 1991. This paper is a portion of a thesis submitted by R.K. in parital fulfillment of MS degree requirements. The cost of publishing this paper was defrayed in part by the payment of page charges. Under postal regulations, this paper therefore must be hereby marked advertisemen $t$ solely to indicate this fact.

'Present address: Dept. of Horticulture, Iowa State University, Ames, IA 50011.

'Present address: Agronomy Dept., 605 Bradfield Hall, Cornell University, Ithaca, NY 14853. same orthostichery, indicating the role of a flowering inhibitor (Harder et al., 1949). Schawbe (1985) has presented convincing evidence for the involvement of a flowering inhibitor.

For commercial forcing, flowering lateral shoots are often equal to if not more important than the terminal inflorescence in terms of overall flower counts. However, the extent of lateral shoot development varies considerably between cultivars. Securing an understanding of factors that control flowering of lateral buds would prove beneficial in determining how cultivars vary in this respect. An important first step is to determine the anatomy at the leaf axil and whether the extent of vascular development is associated with lateral bud development and initiation. The purpose of this study was to determine the arrangement of vascular tissues to leaves ment in floral initiation of lateral buds.

Sixty-three cuttings each of 'Cactus Candy', 'Gelbe Melody', and 'Jupiter' were taken from stock plants, directly stuck in $9 \times 10-\mathrm{cm}$ (height $\mathrm{x}$ width) pots containing medium [1 sphagnum peat : 1 soil : 1 perlite (by volume)], and placed under intermittent mist for 2 weeks. The stock plants and cuttings were maintained under long days using 50 $\mu \mathrm{mol} \cdot \mathrm{m}^{-2} \cdot \mathrm{s}^{-1}$ incandescent lighting from 10 PM to $2 \mathrm{AM}$. After propagation, each plant was treated with $0.8 \mathrm{~g}$ slow-release fertilizer (14N-6.2P-11.6K, Osmocote, Sierra Chemical, Milpitas, Calif.) and $0.4 \mathrm{~g}$ aldicarb (Temik; Union Carbide, Research Triangle Park, N.C.). Plants were then placed in growth rooms with a 9-h photoperiod at a constant $21 \mathrm{C}$. Illumination was provided by fluorescent $(40 \mathrm{~W}, 120 \mathrm{~V})$ and incandescent lamps with a light intensity of 660 $\mu \mathrm{mol} \cdot \mathrm{m}^{-2} \cdot \mathrm{s}^{-1}$ on the perimeter and 876 $\mu \mathrm{mol} \cdot \mathrm{m}^{-2} \cdot \mathrm{s}^{-1}$ at the center. Plants were watered when the soil appeared dry.

For 21 days after the beginning of short days, three plants of each cultivar were removed and tissue samples taken of the upand lateral buds in kalanchoe and its involve-

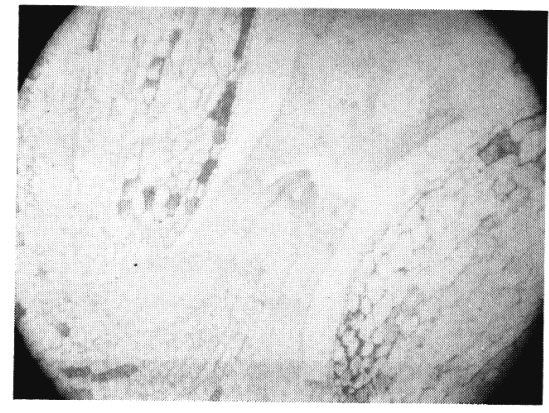

Fig. 1. Lateral spice form the third node of 'Gelbe Melody' after 21. short days.

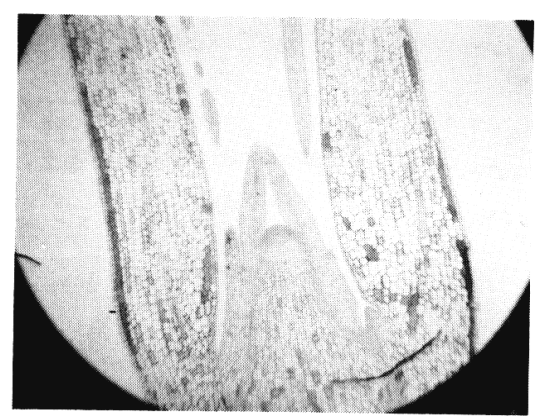

Fig. 2. Lateral spice form the third node of 'Jupiter' after 21 short days.

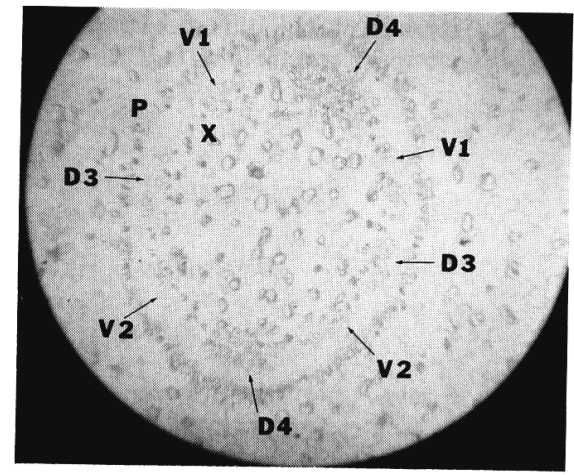

Fig. 3. Cross section of a kalanchoe stem about one-half the distance between the fourth and fifth nodes; P, phloem; X, xylem; D4, dorsal bundles to leaves at the fourth node; D3, dorsal bundles to leaves at the third node; V1-V2, ventral bundles supplying opposite leaf pairs at the fourth and third nodes.

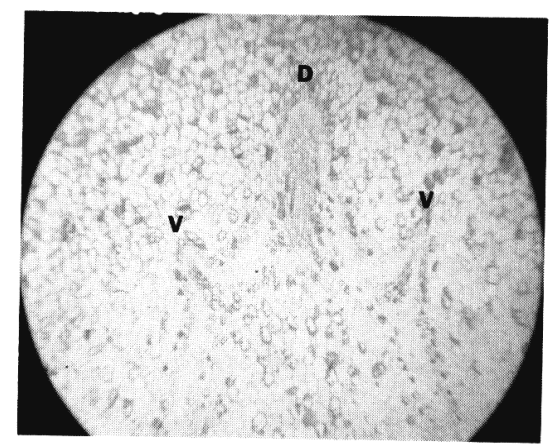

Fig. 4. Cross section of the stem about one-fourth of the way below node 4 . D, dorsal bundle to a leaf at the fourth node; $\mathrm{V}$, ventral bundles to a leaf at the fourth node. 


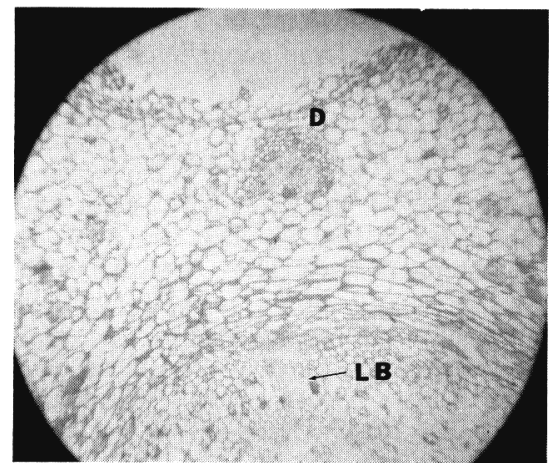

Fig. 5. A cross section just below the fourth node. $\mathrm{D}$, dorsal bundle to a leaf at the fourth node; $\mathrm{LB}$, vascular bundles to the lateral bud at the fourth node.

permost three nodes just below the apex. The first node was in the most acropetal position and possessed leaves recently unfolded from the apex while the third had leaves that were essentially fully expanded. Node sections were excised $\approx 5 \mathrm{~mm}$ above and below the node line and leaves were removed with 3 to 5 $\mathrm{mm}$ of petiole remaining. Each section was then cut in half vertically, perpendicular to the node line. Also, samples of node and internode regions were taken from vegetative stock plants for a study of the vascular arrangement. Samples were cut $5 \mathrm{~mm}$ above the fourth node and $5 \mathrm{~mm}$ below the fifth node to assure sampling a region with fully developed vascular tissue but small enough to be managed microscopically. Leaves were removed with 3 to $5 \mathrm{~mm}$ of petiole remaining on the stem.

All tissues were preserved with a killing and fixing solution [18 ethanol : 1 glacial acetic acid : 1 formalin (by volume)]. A butyl alcohol series was used for dehydration (Jensen, 1962), followed by embedding with paraffin (melting point $56.4 \mathrm{C}$ ), sectioned to $10-\mu \mathrm{m}$-thick ribbons and mounting on glass slides using Haupt's adhesive (Johansen, 1940). Staining of slides was accomplished using a safranin/fast-green system.

Sections of lateral buds for all three cultivars exhibited an overall increase in size and degree of organelle differentiation basipetal from the apex; 'Jupiter' exhibited the greatest degree of lateral bud development while 'Cactus Candy' showed the least. Over the first 18 days of the experiment, 'Cactus Candy' showed no signs of procambial differentiation between any of the three lateral bud positions and the stem vascular tissues. 'Gelbe Melody' showed no signs of differentiation to the first bud position, partial or, in some cases, complete differentiation to the second position, and complete differentiation to the third position. 'Jupiter' showed distinct procambial differentiation at all three lateral bud positions.

The first morphological expression of a change in the terminal apex of kalanchoe from a vegetative to reproductive state was an increase in height and width of the apical dome (Fredericq, 1960; Roodenburg, 1939; Runger, 1968). However, none of these changes could be found in lateral buds of the three
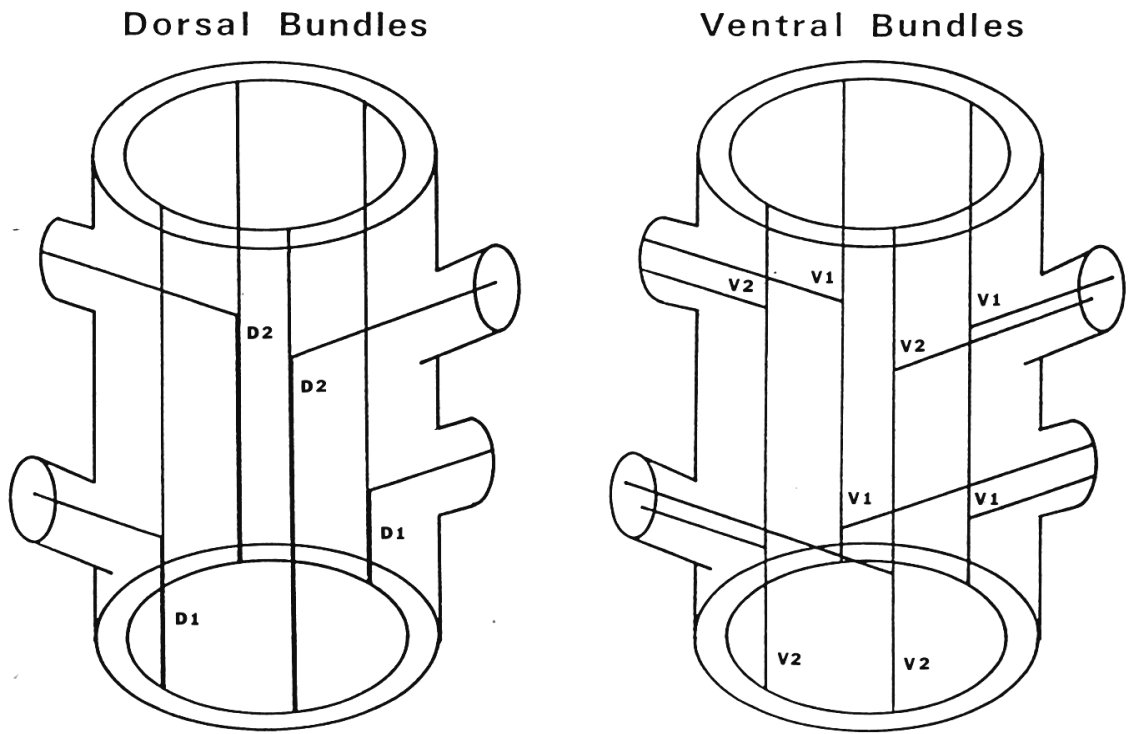

Fig. 6. Proposed three-dimensional arrangement of dorsal bundles in the kalanchoe stem. D1, dorsal bundles supplying leaves in one orthostichery; D2, dorsal bundles supplying leaves in the orthostichery above.

cultivars as long as buds were $<5 \mathrm{~mm}$ long. A typical vegetative lateral bud for 'Gelbe Melody' after 21 short days is shown in Fig. 1. Absence of floral expression was found even though all the buds for 'Jupiter' and buds at the third node for 'Gelbe Melody' had differentiated procambial strands. A few samples taken 19, 20, and 21 days after the beginning of short days were larger than 5 $\mathrm{mm}$, had differentiated procambial strands, and possessed expanding leaves. None of these buds for 'Cactus Candy' or 'Gelbe Melody' showed signs of a change to the floral state. However, larger buds for ' Jupiter' at nodes 3, 2, and 3 after 19, 20, and 21 short days, respectively, did show a change to the floral state (Fig. 2). Flower initiation, therefore, does not seem to be correlated with vascular development to lateral buds. However, we could not determine when these procambial strands became functional in translocation. Since photoperiod perception is in the leaves (Runger, 1968), there must be a means of translocation between leaves and lateral buds for induction to manifest itself in flower initiation and development. Therefore, observations were made on the vascular arrangement within the stem. A transverse section of a 'Cactus Candy' stem an equal distance between nodes 4 and 5 down from the shoot tip is shown in Fig. 3. The cambium at the internode consists of phloem $(\mathrm{P})$ to the outside and xylem $(\mathrm{X})$ to the inside and eight vascular bundles that are closely associated with the inner face of the vascular ring. Bundles D4 will become dorsal bundles supplying leaves at the fourth node while bundles D3 will become dorsal bundles supplying leaves at the third node. The four remaining bundles will become ventral bundle pairs (V1 and V2) supplying the two leaves at the fourth node, but each
Fig. 7. Proposed three-dimensional arrangement of ventral bundles in the kalanchoe stem. V1$\mathrm{V} 2$, ventral bundles supplying the same leaf in one orthostichery but the proximal half of opposite leaves in the orthostichery above.

bundle pair will supply opposite leaves at the third node. As the fourth node is approached acropetally, leaf traces begin to diverge from bundles D and V below the node (Fig. 4). The larger central trace (D) will connect the dorsal bundle of the leaf while the two outside traces $(\mathrm{V})$ will connect the ventral bundles. Figure 5 shows a section just below the junction of petiole and stem. The dorsal bundle to the leaf (D) is evident while an outgrowth from the vascular cambium (LB) that will connect to the lateral bud has begun.

We propose a schematic arrangement of vascular strands in the opposite and decussate orthostichery common to kalanchoe (Figs. 6 and 7). There were four dorsal bundles; bundle pairs D1 supply leaves in one orthostichery while bundle pairs D2 supply leaves in the orthostichery above (Fig. 6). Four ventral bundles supplied leaves at a node, two bundles per leaf (Fig. 7). One bundle from each of these leaves supplies a leaf at the next node on the proximal half of the opposite orthostichery. If a single leaf at the first node received short days, then the succulence-inducing factor associated with flowering could pass acropetally along the orthostichery by dorsal bundles to the third node. The stumulus could also be transported to the proximal half of leaves on the opposite orthostichery at the second node by ventral bundles.

Results reported previously (Harder and Gummer, 1944; Stein and Stein, 1960) support this scheme of transport. Leaves produced under long days by kalanchoes are fairly thin and flexible while those produced under short days are smaller, thicker, and more rigid. If a single leaf is exposed to short days while the rest of the plant receives long days, all those leaves that arise above the former in the same orthostichery will be small, thick, 
and rigid. Those leaves produced on the adjoining orthostichery will be affected, but only on the proximal half. Stein and Stein (1960) proposed that this effect was due to a degree of lateral spread of a photomorphogenic stimulus along the translocation path. However, the presence of separate dorsal bundles for each orthostichery and two ventral bundles from a leaf supplying the proximal half of each leaf in the opposite orthostichery provides a direct path for movement of the stimulus observed in previous studies.

Many plants exhibit early development of lateral buds as one expression of evocation events leading to flowering (Bemier et al., 1981). 'Cactus Candy', 'Gelbe Melody', and 'Jupiter' began exhibiting early development of upper lateral buds after $\approx 18$ short days, although this varied among the cultivars. The degree of lateral bud development for the three cultivars correlates well with observations of unpinched plants grown under short days in the greenhouse, i.e., 'Cactus Candy' was the least self-branching, 'Gelbe Melody' was moderately so, and 'Jupiter' was the most self-branching (data not shown). Over the course of the experiment, none of the lateral buds that were $<5 \mathrm{~mm}$ long showed signs of floral initiation, even though all buds for 'Jupiter' and buds at the third node for 'Gelbe Melody' had differentiated procambial strands. Larger buds sampled on days 19, 20, and 21 for 'Cactus Candy' and 'Gelbe Melody' showed no signs of floral initiation while those for 'Jupiter' did. Thus, the presence of vascular strands to lateral buds does not predispose these buds to flower. Differentiation of vascular strands began at the vascular cambium and progressed to the lateral bud. These strands were not associated with vascular bundles supplying the leaves. Thus, if there were no lateral spread of the flowering stimulus out of leaf bundles, then lateral buds might be isolated and floral initiation in lateral buds could be a separate event requiring the presence of maturing, photoperiodically receptive leaves. Alternately, since it is known that the flowering stimulus in kalanchoes is translocated, even across graft unions that have differentiated vascular tissue (Carr and Melchers, 1954), the possibility exists that the floral stimulus can spread laterally out of the stem vascular bundles to lateral buds. Many of the buds examined were very small and probably still under the influence of apical dominance or had just begun to grow. Even so, many of the buds for 'Gelbe Melody' and 'Jupiter' possessed differentiated procambial tissue. Since only larger lateral buds for 'Jupiter' exhibited a transition to the floral state, it would seem that lateral buds must reach some definite state of maturity to be receptive to floral stimulus from the rest of the plant. Since strong support exists for the production of a flowering inhibitor under long days, isolated lateral buds under short days might have to reach some state of photo-receptive maturity to perceive the short-day induction.

These results suggest that, as the terminal bud of kalanchoes progresses toward flowering, lateral buds are released to grow earlier when compared with vegetative buds at the same node position relative to the apex. Differentiation of provascular strands to supply these buds accompanies their growth. However, the presence of complete vascular connections does not predispose buds to flower. The proposed arrangement of vascular bundles within the stem of kalanchoe adequately explains previous observations concerning movement of a photomorphogenie stimulus within the plant. Since vascular connections supplying lateral buds arise from vascular cambium and are not directly connected to stem vascular bundles, induc- tion in lateral buds may be a separate event requiring leaves large enough for photo-reception.

\section{Literature Cited}

Bemier, G., J.M. Kinet, and R.W. Sacks. 1981. The nature of floral evocation. The physiology of flowering V-II. CRC Press, Boca Raton, Fla.

Carr, D.J. and G. Melchers. 1954. Auslösung von Blütenbildung bie der Kurztagflanze Kalanchoe blossfeldiana in Langtagbedingungen durch Pfropfpartner. Z. Naturforsch. 89:216-218.

Fredericq, H. 1960. The change of the apex of Kalanchoe blossfeldiana toward inflorescence formation. Bio. Jaar. 410, B52, 28:76-80.

Harder, R. and G. Gummer. 1944. Weiteres über örtlich beschränkte Wirkung und Leitung des formbeeinflussenden Metaplasins. Jahr. Wiss. Bot. 91:359-380.

Harder, R. and H.V. Witsch. 1940. Üder die Einwirkung von Kurztagsblättern auf im Langtag befindliche Blätter und Stengelteile der gleichen Pflanze. Planta 31:523-558.

Harder, R., M. Westphal, and G. Behrens. 1949. Hemmung der Infloreszenzbildung durch Langtag bei der Kurztagpflanze Kalanchoe blossfeldiana. Plant 36:424-438.

Jensen, W.A. 1962. Botanical histochemistry. W.H. Freeman, San Francisco.

Johansen, D.A. 1940. Plant microtechnique. 1st ed. McGraw-Hill, New York.

Roodenburg, J.W.M. 1939. Vervroeging von de bloei bij Kalanchoe blossfeldiana Weekbl. u. d. Kon. Ned. Mij u. Tuing. en Plantenk. 13:1 (in The induction of flowering: Some case histories, 1969.)

Runger, W. 1968. Studies on the role of the leaf epidermis in photoperiodic perception in Kalanchoe blossfeldiana. J. Expt. Bot. 19:108.

Schawbe, W.W. 1985. kalanchoe blossfeldiana, p 217-235. In: L. Evans (ed.). vol. III. Handbook of flowering. CRC, Boca Raton, Fla.

Stein, D.B. and O.L. Stein. 1960. The growth of the stem tip of Kalanchoe cv. 'Brilliant Star'. Amer. J. Bot. 47:132-139. 